\title{
Enhanced antitumoral activity of doxorubicin against lung cancer cells using biodegradable poly(butylcyanoacrylate) nanoparticles
}

This article was published in the following Dove Press journal:

Drug Design, Development and Therapy

14 December 2015

Number of times this article has been viewed

\author{
Consolación Melguizo ${ }^{1,2, *}$ \\ Laura Cabezal,* \\ Jose Prados 1,2 \\ Raúl Ortiz ${ }^{1,3}$ \\ Octavio Caba',3 \\ Ana R Rama ${ }^{1,3}$ \\ Ángel V Delgado 4 \\ José L Arias ${ }^{1,2,5}$ \\ 'Institute of Biopathology and \\ Regenerative Medicine (IBIMER), \\ Biomedical Research Center, \\ ${ }^{2}$ Biosanitary Institute of Granada \\ (IBS Granada), SAS Universidad de \\ Granada, Granada, ${ }^{3}$ Department of \\ Health Science, University of Jaén, \\ Jaén, ${ }^{4}$ Department of Applied Physics, \\ ${ }^{5}$ Department of Pharmacy and \\ Pharmaceutical Technology, University \\ of Granada, Granada, Spain
}

*These authors contributed equally to this work

\begin{abstract}
Doxorubicin (Dox) is widely used for the combined chemotherapy of solid tumors. However, the use of these drug associations in lung cancer has low antitumor efficacy. To improve its efficacious delivery and activity in lung adenocarcinoma cells, we developed a biodegradable and noncytotoxic nanoplatform based on biodegradable poly(butylcyanoacrylate) (PBCA). The reproducible formulation method was based on an anionic polymerization process of the PBCA monomer, with the antitumor drug being entrapped within the nanoparticle (NP) matrix during its formation. Improved drug-entrapment efficiencies and sustained (biphasic) drug-release properties were made possible by taking advantage of the synthesis conditions (drug, monomer, and surfactant-agent concentrations). Dox-loaded NPs significantly enhanced cellular uptake of the drug in the A549 and LL/2 lung cancer cell lines, leading to a significant improvement of the drug's antitumoral activity. In vivo studies demonstrated that Dox-loaded NPs clearly reduced tumor volumes and increased mouse-survival rates compared to the free drug. These results demonstrated that PBCA NPs may be used to optimize the antitumor activity of Dox, thus exhibiting a potential application in chemotherapy against lung adenocarcinoma.
\end{abstract}

Keywords: lung cancer, cancer chemotherapy, PBCA, polymeric nanoparticles, drug carrier

\section{Introduction}

Lung cancer is the second-most commonly diagnosed cancer in both men and women, representing $\sim 14 \%$ of all newly diagnosed cancers, the most frequent subtype being non-small-cell lung cancer (90\%). Unfortunately, more than $70 \%$ of lung cancer patients have already developed locally advanced or metastatic disease (in the liver, brain, adrenals, kidneys, bones, and pleura, among other sites) by the time they are diagnosed, and less than $16 \%$ have a 5-year survival rate. ${ }^{1}$ Although in these advanced stages, first-line chemotherapy treatment involves cisplatin and carboplatin, other associated chemotherapy drugs (paclitaxel, docetaxel, irinotecan, topotecan, and gemcitabine) are often used, with doxorubicin (Dox) being among the most effective. ${ }^{2}$ Despite good patient-survival rates from these combination-chemotherapy treatments, drug resistance and drug-related toxicity severely limit clinical outcomes. ${ }^{3,4}$ Therefore, strategies that decrease both drug toxicity and resistance may significantly improve lung cancer response to current drug associations. Interestingly, it has recently been demonstrated that the use of nanocarriers for Dox associations improves its antitumoral activity in lung cancer. ${ }^{5}$

More specifically, the antineoplastic drug Dox is a member of the family of antibiotic anthracyclines that exhibits a broad spectrum of antitumoral activity. It is used
Correspondence: Jose Prados Institute of Biopathology and Regenerative Medicine (IBIMER), Biomedical Research Center, University of Granada, Avenida del Conocimiento, Granada 18100, Spain

Tel +34958248 819

Fax +34958246296

Email jcprados@ugr.es 
in the treatment of a large number of tumors because of its significant benefits. In fact, Dox can inhibit the signaling pathway of TGF- $\beta 1$, the upregulation of which has been associated with the development of metastasis, in both lung adenocarcinoma and breast cancer. ${ }^{6-9}$ Unfortunately, its clinical use is restricted due to problems, including 1) its poor target selectivity and rapid clearance from the body, 2) its severe (dose-limiting) toxicity (ie, myelosuppression, cardiotoxicity, and nephrotoxicity), and 3) resistance mechanisms developed by malignant cells (Dox is a substrate for multidrug-resistant proteins, inducing the inactivity of the drug, eg, P-glycoprotein is a membrane protein that acts as an ATP-dependent flux pump reducing Dox concentrations in tumor cells). ${ }^{10-12}$ In this context, many nanocarriers (eg, solid polymer-lipid hybrids and chitosan-based nanoplatforms) have been proposed to overcome these challenges and maximize the clinical efficacy of Dox. ${ }^{5,13}$ Poly(alkylcyanoacrylate) nanoplatforms have demonstrated good vehiculization capabilities for antitumor drugs and the potential to optimize both in vitro and in vivo antitumoral effects. ${ }^{14-16}$ For instance, surfactant-coated poly(butylcyanoacrylate) (PBCA) nanoparticles (NPs) loaded with epirubicin and etoposide have demonstrated greater cytotoxicity against A549 human lung adenocarcinoma cells. ${ }^{17,18}$ Interestingly, it has been hypothesized that PBCA NPs could overcome the P-glycoprotein-related cellular mechanism of multidrug resistance. ${ }^{14}$ This effect helps to enhance the activity of the drug against tumoral cells, and has also been described for other NPs, such as micelles, liposomes, solid lipid NPs, and dendrimers. ${ }^{19,20}$ Finally, PBCA NPs may transport drugs across the blood-brain barrier to the brain. ${ }^{21}$ These results support the idea that PBCA NPs are a good candidate for drug loading, including Dox against tumor cells.

For this study, we developed a reproducible synthesis method for preparing Dox-loaded PBCA NPs by modifying formulation conditions (drug, monomer, and surfactant-agent concentrations) in order to assure maximum drug-loading efficiencies and a sustained drug-release profile. We demonstrated that PBCA NPs do not exhibit any cytotoxicity on their own, and we were able to enhance, both in vitro and in vivo, the antitumoral effect of Dox against A549 and LL/2 lung cancer cells. We describe how the Dox-loaded NP system can significantly reduce the drug dose necessary to induce in vitro tumor-cell death and a more effective in vivo reduction in tumor volume than with the free drug. Therefore, our (nano)-formulation may be a candidate for minimizing the toxicity and improving the effectiveness of Dox in patients with advanced lung cancer.

\section{Materials and methods Materials}

All the chemicals were purchased from Sigma-Aldrich Co (St Louis, MO, USA), with the exception of BCA (Henkel AG \& Co KGaA, Düsseldorf, Germany) and Dox hydrochloride (Dr M Damas, San Cecilio Hospital, Granada, Spain).

\section{Cell lines}

The human lung carcinoma cell line A549 and the mouse Lewis lung carcinoma cell line LL/2 were obtained from the Scientific Instrumentation Center (University of Granada, Granada, Spain) and the American Type Culture Collection, respectively. They were maintained under culture conditions $\left(37^{\circ} \mathrm{C}\right.$ and a humidified atmosphere of $5 \% \mathrm{CO}_{2}$ in air) in Dulbecco's modified Eagle's medium (DMEM) supplemented with $10 \%$ heat-inactivated fetal bovine serum and $1 \%$ of a mixture of antibiotics $(10,000 \mathrm{U} / \mathrm{mL}$ penicillin and $10 \mathrm{mg} / \mathrm{mL}$ streptomycin).

\section{Preparation of poly(butylcyanoacrylate) nanoparticles}

The polymeric NPs were synthesized by emulsion/ polymerization of the BCA monomer as described previously, with significant modifications. ${ }^{22}$ This involved $0.3 \mathrm{~mL}$ of an acetonic solution of the monomer $(1 \%, \mathrm{w} / \mathrm{v})$ being added dropwise to $3 \mathrm{~mL}$ of an aqueous solution containing $0.1 \mathrm{mN} \mathrm{HCl}$ and dextran $70(0.5 \%, \mathrm{w} / \mathrm{v})$ under mechanical stirring (3,000 rpm). Polymerization continued for 4 hours. Next, $3 \mu \mathrm{L}$ of a $0.1 \mathrm{M} \mathrm{NaOH}$ solution was added to neutralize the medium, ensuring the total consumption of the monomer. Finally, acetone was removed from the NP dispersion through evaporation with a rotary evaporator (Rotavapor ${ }^{\circledR}$, Büchi Labortechnik AG, Flawil, Switzerland), and the NPs were cleaned by several centrifuge cycles (10 minutes at 10,000 rpm, Centrikon T-124 high-speed centrifuge; Kontron AG, Augsburg, Germany) until the conductivity of the supernatants was $\leq 10 \mu \mathrm{S} / \mathrm{cm}$.

Dox entrapment was done by incorporating adequate quantities of the drug (up to $0.01 \mathrm{M}$ ) into the acetonic solution of the monomer, prior to starting the formulation procedure (as described earlier). All steps of the NP synthesis were kept unaltered. The effects on Dox entrapment of the dextran-70 concentration in the aqueous phase and BCA monomer in the organic solution were evaluated by varying these concentrations from 0 to $1 \%(\mathrm{w} / \mathrm{v})$ and between 0.5 and $3 \%(\mathrm{w} / \mathrm{v})$, respectively. The production performance (yield, \%) of each of the preparation conditions was determined: 


$$
\text { Yield }(\%)=\frac{\begin{array}{c}
\text { Amount of NPs } \\
\text { loaded with drug }
\end{array}}{\begin{array}{c}
\text { Sum of materials used in the } \\
\text { synthesis of these NPs }
\end{array}} \times 100
$$

The nanoformulations were prepared under aseptic conditions in a sterile laminar flow hood, and care was taken to avoid environmental contamination of the samples during manufacture and prior to injection into animals.

\section{Particle size and surface electrical properties}

Mean diameters of the blank (Dox-unloaded) PBCA NPs and the Dox-loaded PBCA NPs were measured in sextuplicate at $25.0^{\circ} \mathrm{C} \pm 0.5^{\circ} \mathrm{C}$ by photon correlation spectroscopy (Autosizer 4700 with the scattering angle set at $60^{\circ}$; Malvern Instruments Ltd, Malvern, UK). Dilutions of the aqueous NP dispersions $(\sim 0.1 \%, w / v)$ were made before the determinations. Particle size was also determined after 2 months of storage in water at $4.0^{\circ} \mathrm{C} \pm 0.5^{\circ} \mathrm{C}$ to evaluate NP stability.

Surface electrical properties of both blank and drugloaded NPs $(\sim 0.1 \%, \mathrm{w} / \mathrm{v})$ were determined by electrophoresis at $25.0^{\circ} \mathrm{C} \pm 0.5^{\circ} \mathrm{C}$ (Zetasizer 2000 electrophoresis device; Malvern Instruments). These measurements were made after the NPs had been in contact with water for 24 hours (at pH 5 and $1 \mathrm{mM} \mathrm{KCl}$ ) under mechanical stirring (50 rpm) at the same temperature. The O'Brien and White theory was used to transform the electrophoretic mobility $\left(u_{\mathrm{e}}\right)$ data into $\zeta$-potential values. ${ }^{23}$ Such electrokinetic characterization was expected to contribute to elucidation of the type of Dox loading in the NPs: entrapment into the matrix, or adsorption onto the particle surface.

\section{Dox-loading and -release determinations}

Ultraviolet-visible (UV-vis) absorption analysis (8500 UV-vis spectrophotometer; Dinko Instruments, Barcelona, Spain) was performed in quadruplicate at $481 \mathrm{~nm}$ to determine Dox concentration in the NP samples, ie, supernatants obtained by filtration of aliquots of the NP dispersions through a membrane filter (pore size $0.1 \mu \mathrm{m}$ ). The supernatant produced under the conditions of drug-loading and -release experiments, but without the drug, was used as a blank to remove others sources of variation in determining Dox concentrations, ie, products of polymer degradation. ${ }^{24}$ No Dox adsorption onto the filter membrane was detected spectrophotometrically. Reproducibility and good linearity, precision, and accuracy of the determinations were assured in all the conditions tested.
Drug-entrapment efficiency (\%) and drug-loading (\%) values were calculated:

$$
\begin{gathered}
\text { Drug-entrapment } \\
\text { efficiency (\%) }
\end{gathered}=\frac{\begin{array}{c}
\text { Mass of drug } \\
\text { incorporated }(\mathrm{mg})
\end{array}}{\begin{array}{c}
\text { Initial drug added to the } \\
\text { medium (mg) }
\end{array}} \times 100
$$

$$
\text { Drug loading }(\%)=\frac{\begin{array}{c}
\text { Mass of drug incorporated } \\
\text { in the NP matrix }(\mathrm{mg})
\end{array}}{\begin{array}{l}
\text { Mass of drug loaded } \\
\text { polymeric NPs }(\mathrm{mg})
\end{array}} \times 100
$$

Dox-release experiments were based on the dialysis-bag method. The experiments were carried out in quadruplicate with the Dox-loaded PBCA NPs characterized by greater drug-entrapment efficiency $(\sim 80 \%$, for those prepared with a $0.01 \mathrm{M}$ drug concentration, $1 \%(\mathrm{w} / \mathrm{v})$ monomer concentration, and $1 \%(\mathrm{w} / \mathrm{v})$ dextran-70 concentration; Table 1). We used phosphate-buffered saline (PBS; pH 7.4) or $\mathrm{pH} 5.0$ maintained at $37.0^{\circ} \mathrm{C} \pm 0.5^{\circ} \mathrm{C}$ as the receiving phase. The bags were soaked in PBS for 12 hours, and then $1 \mathrm{~mL}$ of a Dox-loaded NP dispersion ( $4 \mathrm{mg} / \mathrm{mL}$ of drug) was added; the ends were closed with clamps. NPs were retained in the dialysis bag (2,000 Da cutoff; Spectra/Por ${ }^{\circledR} 6$ dialysis membrane tubing; Spectrum Laboratories Inc, Rancho Dominguez, CA, USA), whereas Dox was able to diffuse into the receiving medium. After that, the bags were brought into contact under stirring $(200 \mathrm{rpm})$ with $0.05 \mathrm{~L}$ of the receiving phase (pH 7.4 or 5.0) in a conical flask over different time periods $(0.25,0.5,0.75,1,3,6,9,12,18$, and 24 hours). Then, $2 \mathrm{~mL}$ of the receiving medium were measured using UV-vis spectrophotometric analysis. The sample obtained was replaced into the release phase with an equal volume of release medium.

\section{Proliferation assays with Dox and Dox- loaded PBCA NPs}

Cultured cells were detached with a trypsin-ethylenediaminetetraacetic acid (EDTA) solution $(0.25 \%)$ and seeded into 24-well plates at a density of $15 \times 10^{3}$ A549 cells/well and $2 \times 10^{4} \mathrm{LL} / 2$ cells/well. After incubation for 24 hours under culture conditions, the cells were treated with either free Dox (aqueous solution), blank (Dox-unloaded) PBCA NPs, or Dox-loaded PBCA NPs in increasing drug-equivalent concentrations from 0.01 to $10 \mu \mathrm{M}$. After an incubation time of 48 hours, a modified sulforhodamine B (SRB) protocol was followed. ${ }^{25}$ The cells were washed three 
Table I Dox-entrapment efficiency in poly(butylcyanoacrylate) NPs

\begin{tabular}{|c|c|c|c|c|c|c|}
\hline $\begin{array}{l}\text { Dox } \\
\text { (M) }\end{array}$ & $\begin{array}{l}\text { Butylcyanoacrylate } \\
(\%, w / v)\end{array}$ & $\begin{array}{l}\text { Dextran } \\
70(\%, w / v)\end{array}$ & Size $(\mathrm{nm})$ & $\begin{array}{l}\text { Dox-entrapment } \\
\text { efficiency (\%) }\end{array}$ & $\begin{array}{l}\text { Production } \\
\text { performance (\%) }\end{array}$ & $\zeta(\mathrm{mV})$ \\
\hline 0 & 1 & 0.5 & $73 \pm 12$ & - & $96 \pm 3$ & $-23 \pm 5$ \\
\hline $10^{-4}$ & I & 0.5 & $68 \pm 15$ & $44 \pm 3$ & $95 \pm 2$ & $-26 \pm 3$ \\
\hline $5 \times 10^{-4}$ & I & 0.5 & $74 \pm 11$ & $57 \pm 4$ & $96 \pm 1$ & $-24 \pm 4$ \\
\hline $10^{-3}$ & 1 & 0.5 & $77 \pm 12$ & $66 \pm 3$ & $96 \pm 3$ & $-22 \pm 4$ \\
\hline $5 \times 10^{-3}$ & 1 & 0.5 & $83 \pm 14$ & $74 \pm 4$ & $97 \pm 1$ & $-27 \pm 5$ \\
\hline $10^{-2}$ & 1 & 0.5 & $78 \pm 13$ & $79 \pm 3$ & $95 \pm 2$ & $-25 \pm 6$ \\
\hline $10^{-2}$ & 1 & 0 & Macroaggregates & $3 \pm 1$ & $2 \pm 1$ & $-23 \pm 4$ \\
\hline $10^{-2}$ & I & 1 & $81 \pm 15$ & $77 \pm 3$ & $97 \pm 2$ & $-28 \pm 3$ \\
\hline $10^{-2}$ & 0.5 & 0.5 & $76 \pm 13$ & $79 \pm 4$ & $95 \pm 2$ & $-23 \pm 6$ \\
\hline $10^{-2}$ & 2 & 0.5 & $77 \pm 14$ & $78 \pm 4$ & $97 \pm 1$ & $-27 \pm 4$ \\
\hline $10^{-2}$ & 3 & 0.5 & $82 \pm 12$ & $77 \pm 2$ & $96 \pm 2$ & $-26 \pm 5$ \\
\hline
\end{tabular}

Notes: Effect of the formulation conditions (Dox, butylcyanoacrylate monomer, and dextran-70 concentrations) for drug entrapment on particle size, Dox-entrapment efficiency (\%), production performance (yield, \%), and $\zeta$-potential $(\mathrm{mV})$ values of the blank (Dox-unloaded) PBCA NPs and the Dox-loaded PBCA NPs synthesized after drug dissolution in the organic phase. Dox concentrations (M) incorporated into the acetonic solution of the monomer. Results expressed as mean \pm SD of quadruplicate experiences.

Abbreviations: Dox, doxorubicin; NPs, nanoparticles; PBCA, poly(butylcyanoacrylate); SD, standard deviation.

times with PBS, and $300 \mu \mathrm{L}$ of $10 \%$ trichloroacetic acid was used to fix the cells $\left(20\right.$ minutes at $\left.4^{\circ} \mathrm{C}\right)$. Then, the cells were washed three times with distilled water and left to dry before $300 \mu \mathrm{L}$ of SRB was added again. Incubation under mechanical stirring was continued for 20 minutes, and the excess SRB was removed by the addition of a $1 \%$ acetic acid solution. Then, the cells were left to dry. Finally, $200 \mu \mathrm{L}$ of Trizma ${ }^{\circledR}$ (10 mM, pH 10.5; Sigma-Aldrich) was used for dye resuspension. The optical density (OD) of SRB was measured at $492 \mathrm{~nm}$ (Titertek ${ }^{\circledR}$ Multiskan colorimeter; Flow Laboratories Ltd, Oldham, UK) and analyzed with Ascent software version 2.6 (Thermo Labsystems, Helsinki, Finland).

The percentage of relative proliferation (RP, \%) was calculated:

$$
\mathrm{RP}(\%)=\frac{\mathrm{OD} \text { of treated cells }}{\mathrm{OD} \text { of untreated cells }} \times 100
$$

\section{FACScan flow cytometry and fluorescent microscopy}

Plates of six wells were seeded with either A549 cells or LL/ 2 cells $\left(15 \times 10^{4}\right.$ cells/well $)$ in $2 \mathrm{~mL}$ of complete DMEM, and were maintained under culture conditions for 24 hours. Then, the cells were incubated over $0.5,1,1.5,2$, and 4 hours with free Dox (aqueous solution) or Dox-loaded PBCA NPs at a drug-equivalent concentration of $43.1 \mu \mathrm{M}$ (high dose) to observe the cellular internalization. The cells were detached with the trypsin-EDTA solution $(0.25 \%)$. Data were collected using a FACSCanto II flow cytometer (BD Biosciences, San Jose, CA, USA) and analyzed using FACSDiva software (BD Biosciences). At these contact times, the cells were further observed under a DM IL LED fluorescence microscope (Leica Microsystems, Wetzlar, Germany).

In addition, the localization of the Dox-loaded NPs in the A549 and LL/2 cells was investigated. The cells were seeded in eight-well chamber slides (BD Biosciences) $\left(5 \times 10^{3}\right.$ cells/well). After incubation for 24 hours, the cells were incubated for a further hour with either free Dox (aqueous solution) or Dox-loaded PBCA NPs at drug-equivalent concentrations of 10 and $43.1 \mu \mathrm{M}$ (high dose) to observe cellular internalization. Then, the cells were fixed with a $4 \%$ formaldehyde solution for 20 minutes and washed three times with PBS. After this, the samples were prepared with a mounting medium containing 4',6-diamidino-2phenylindole (Thermo Fisher Scientific, Waltham, MA, USA), prior to observation under the Leica DM IL LED fluorescence microscope.

\section{In vivo antitumoral activity}

This study was approved by the ethics committee of the University of Granada. Animals used in the in vivo study were manipulated in a temperature-controlled room at $22^{\circ} \mathrm{C}$ approximately with a 12 hour light/dark cycle. C57BL/6 female mice ( $\mathrm{n}=40$, weight $18-20 \mathrm{~g}$, age 6 weeks; Charles River Laboratories Inc, Wilmington, MA, USA) were inoculated subcutaneously in the right hind flank with $200 \mu \mathrm{L}$ of PBS containing $5 \times 10^{5} \mathrm{LL} / 2$ cells. After 9 days, when tumors were palpable, the mice were divided into four groups and treated every 3 days (over 39 days) with a total of five doses (equivalent drug concentration of $10 \mathrm{mg} / \mathrm{kg}$ ) of control (untreated mice), free Dox (aqueous solution), blank (Dox-unloaded) PBCA NPs, or Dox-loaded PBCA 
NPs. At the end of the experiment, all surviving animals were killed.

Prior to each injection, the mice were weighed and the tumor dimensions measured with a digital caliper. Tumor volume $\left(V, \mathrm{~mm}^{3}\right)$ was then calculated:

$$
V\left(\mathrm{~mm}^{3}\right)=\frac{a \cdot b^{2} \cdot \pi}{6}
$$

where $a$ represents the longest length of the tumor and $b$ is the longest line perpendicular to $a$.

\section{Statistical analysis}

Proliferation assays were performed in triplicate, and the data are expressed as means \pm standard deviation. Differences between groups were compared using Student's $t$-test, with a significance level of $0.05(\alpha=0.05)$. Mouse survival was determined by the Kaplan-Meier method, and the survival rates of the groups were compared using the log-rank test $(\alpha=0.05)$. Statistical analysis was carried out with SPSS version 15.0 (IBM Corporation, Armonk, NY, USA).

\section{Results}

\section{Nanoparticle engineering}

Negatively charged and homogeneously sized Dox-loaded NPs (average diameter $\sim 75 \mathrm{~nm}$, polydispersity index $0.064, \zeta \sim-25 \mathrm{mV}$ ) (Table 1) were prepared by emulsion/ polymerization. ${ }^{24,26,27}$ The adequate stability of the NP aqueous dispersions was evaluated after 2 months of storage at $4.0^{\circ} \mathrm{C} \pm 0.5^{\circ} \mathrm{C}$ : under these storage conditions, no aggregates or sediments were observed. In addition, the surface electrical properties ( $\zeta$-values) remained unaltered.

It was found that higher Dox concentrations incorporated into the acetonic solution of the monomer resulted in more drug being loaded into the NP system (Table 1). For example, Dox-entrapment efficiency increased from $44 \% \pm 3 \%$ to $79 \% \pm 3 \%$ when the drug concentrations were raised from $10^{-4}$ to $0.01 \mathrm{M}$. However, the use of dextran 70 (within the range of concentrations tested) only assured the formation of homogeneously sized Dox-loaded NPs, without assisting in drug-entrapment optimization (Table 1). In fact, the yield ( $\%$ ) of NP production (always $\geq 93 \%$ when dextran 70 was used) decreased to $\leq 4 \%$ in the absence of the surfactant agent. Likewise, the concentration of BCA monomer did not contribute to Dox-entrapment efficiency. Interestingly, the electrokinetic analysis of the NP systems highlighted the great similarity between the $\zeta$-values of the blank (drug-unloaded) and drug-loaded NPs (Table 1), thereby proving that from an electrophoretic point of view, the blank and Dox-loaded NPs may be considered identical. It could therefore be concluded that Dox molecules were efficaciously entrapped into the polymeric matrix, rather than just adsorbed at the surface. Finally, drug release from PBCA NPs $\left(\mathrm{pH} 7.4,37^{\circ} \mathrm{C}\right)$ started with a fast-release phase $(\sim 35 \%$ Dox release in 1 hour), followed by a sequential release phase that ended after 23 hours (Figure 1). Interestingly, no significant differences were observed when the Dox-release studies were accomplished at $\mathrm{pH} 5.0$, which can be probably ascribed to the stability of these polymeric matrices in both acidic and neutral media. ${ }^{28,29}$ In vitro and in vivo antitumor studies were performed using the PBCA particles with the greatest Dox-entrapment efficiency, ie, $\sim 80 \%$ (0.01 M Dox concentration incorporated into the acetonic solution of the monomer, Table 1).

\section{In vitro cytotoxicity study}

Blank (Dox-unloaded) PBCA NPs were found to be noncytotoxic in A549 and LL/2 lung cancer cells at the concentrations tested (up to $10 \mu \mathrm{M}$ ) and after 48 hours of $\mathrm{NP}$-cell contact time (Figure 2). On the other hand, Doxloaded PBCA NPs induced a significant decrease in A549 and LL/2 cell proliferation compared to free Dox (aqueous solution) $(P<0.01)$. Interestingly, the half-maximal inhibitory concentration $\left(\mathrm{IC}_{50}\right)$ was significantly decreased by the Dox-loaded polymeric nanoformulation in a timedependent manner (Figure 3): differences between groups were observed after 8 and 24 hours, the most significant divergences being obtained after 48 hours of NP-cell contact. Specifically, Dox-loaded PBCA NPs showed a 2.4fold reduction (from 0.71 to $0.3 \mu \mathrm{M}$ ) and nearly threefold

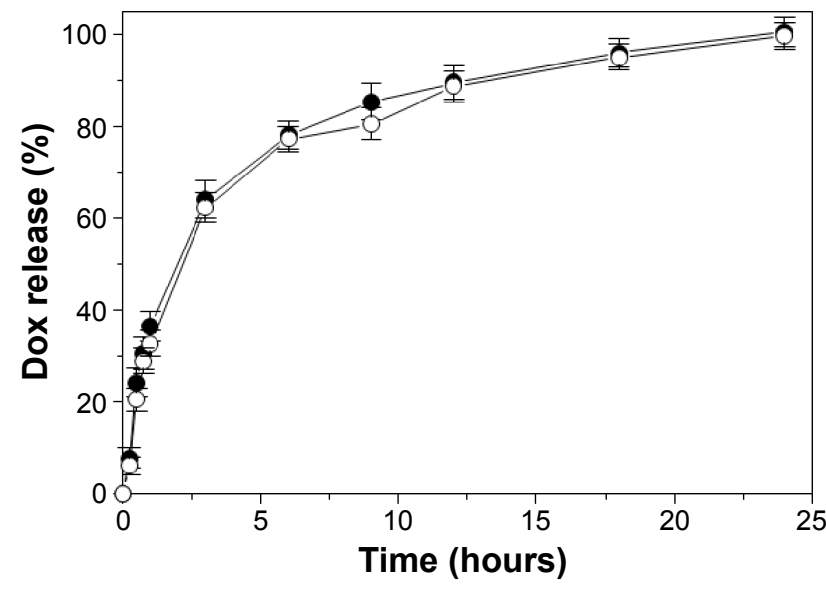

Figure I Release of previously entrapped Dox from PBCA NPs as a function of the incubation time in $\mathrm{PBS} \mathrm{pH} 7.4$ (solid circles) and $\mathrm{pH} 5.0$ (open circles) at $37^{\circ} \mathrm{C}$. Abbreviations: Dox, doxorubicin; PBCA, poly(butylcyanoacrylate); NPs, nanoparticles; PBS, phosphate-buffered saline. 


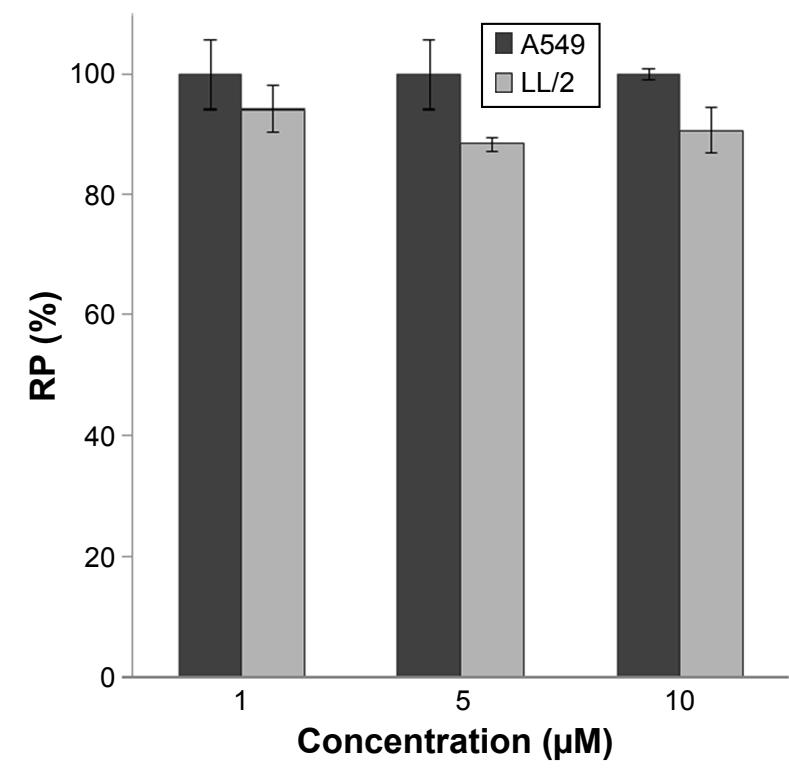

Figure 2 In vitro cytotoxicity of PBCA NPs in lung cancer cells.

Notes: The growth of A549 and LL/2 cell lines was evaluated after exposure to a wide range $(1-10 \mu \mathrm{M})$ of blank (Dox-unloaded) PBCA NPs over 48 hours. Data represent mean \pm SD of triplicate cultures.

Abbreviations: PBCA, poly(butylcyanoacrylate); NPs, nanoparticles; Dox, doxorubicin; RP, relative proliferation; SD, standard deviation. reduction (from 0.11 to $0.04 \mu \mathrm{M}$ ) in the $\mathrm{IC}_{50}$ values of $\mathrm{A}-549$ and LL/2 cell lines, respectively, in comparison to the free drug (Figure 3).

\section{Cell uptake and disposition of Dox- loaded PBCA NPs}

Fluorescence microscopy revealed that cells treated with Doxloaded PBCA NPs displayed greater fluorescence intensities than free Dox at the exposure times investigated (0.5-2 hours) (Figure 4A). In addition, after 2 hours of NP-cell exposure, morphological changes (bubble-like bleb formation on cell surface typical of apoptotic cell death) were exclusively observed in the cells in contact with Dox-loaded PBCA NPs. The flow-cytometry assay confirmed that greater Dox uptake by A549 and LL/2 lung cancer cells was possible when it was entrapped into the PBCA NPs (Figure $4 B$ and C). These images also highlight the significant and progressive increase in Dox uptake (when loaded into the NPs) by A549 cells, in comparison with free Dox: $22.6 \%, 10.9 \%, 34.5 \%, 52.3 \%$, and $64.8 \%$ after $0.5,1,1.5,2$, and 4 hours, respectively. Similar
A
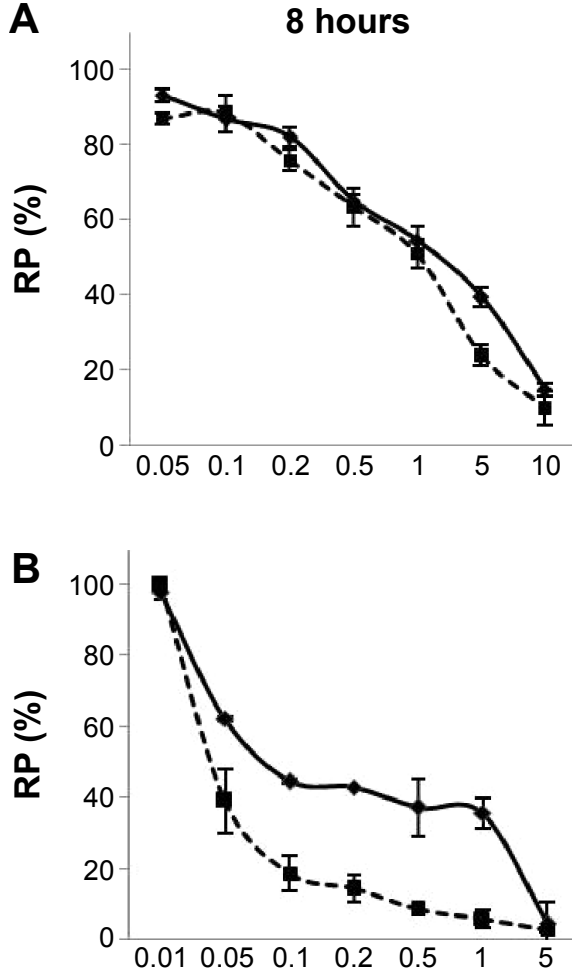

Concentration $(\mu \mathrm{M})$
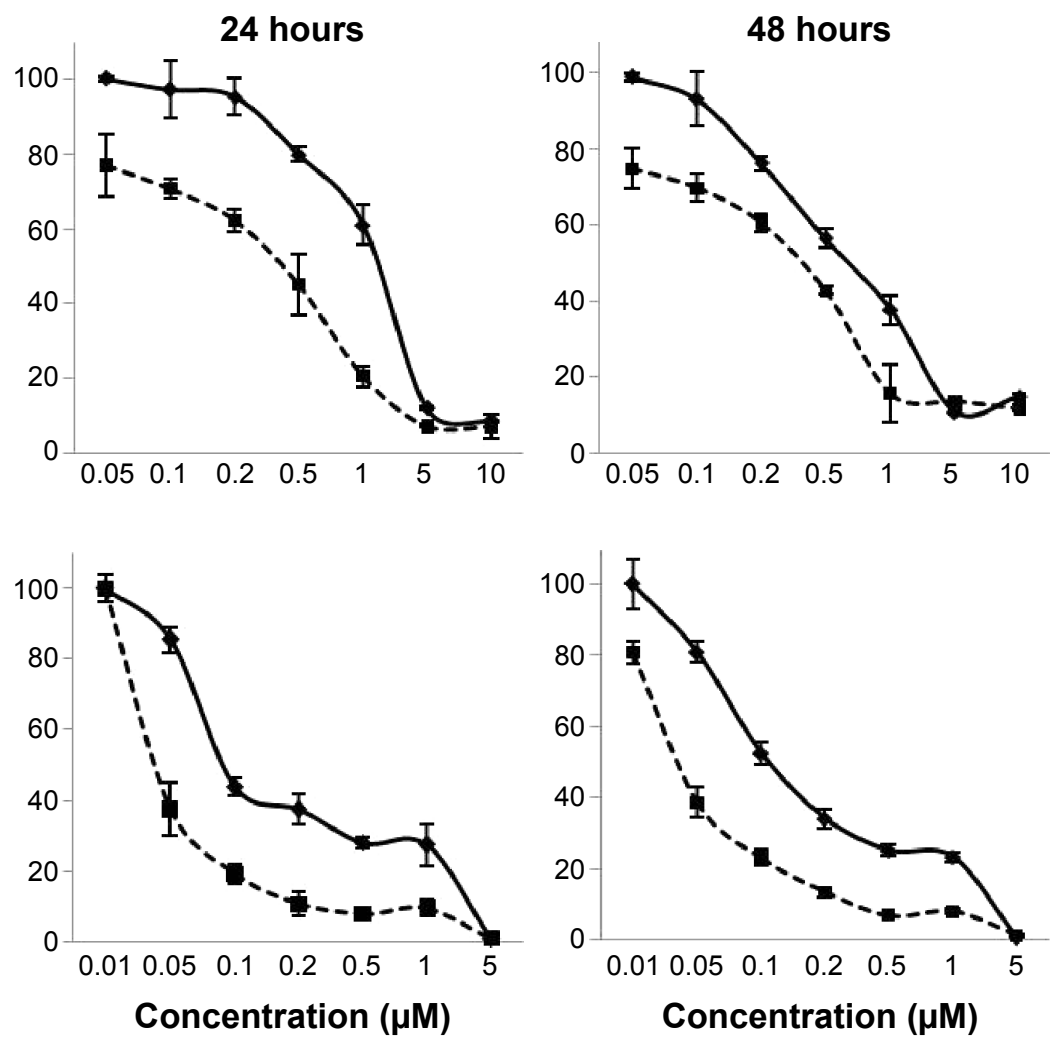

Concentration $(\mu \mathrm{M})$

Figure 3 In vitro cytotoxicity of Dox-loaded PBCA NPs in lung cancer cells.

Notes: Growth of A549 (A) and LL/2 (B) cell lines was evaluated after exposure to a wide range (0.01-10 $\mu$ M) of Dox-loaded PBCA NPs for 8 , 24, and 48 hours in comparison to free Dox treatment. Data represent mean \pm SD of triplicate cultures.

Abbreviations: Dox, doxorubicin; PBCA, poly(butylcyanoacrylate); NPs, nanoparticles; RP, relative proliferation; SD, standard deviation. 
A
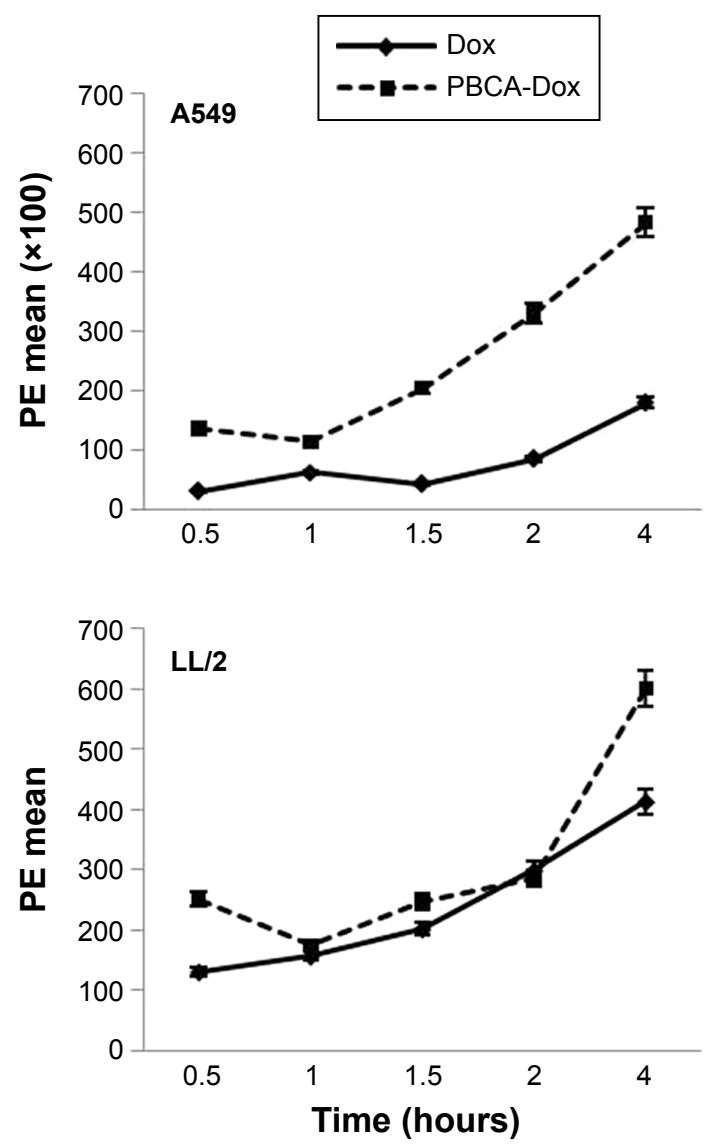

C
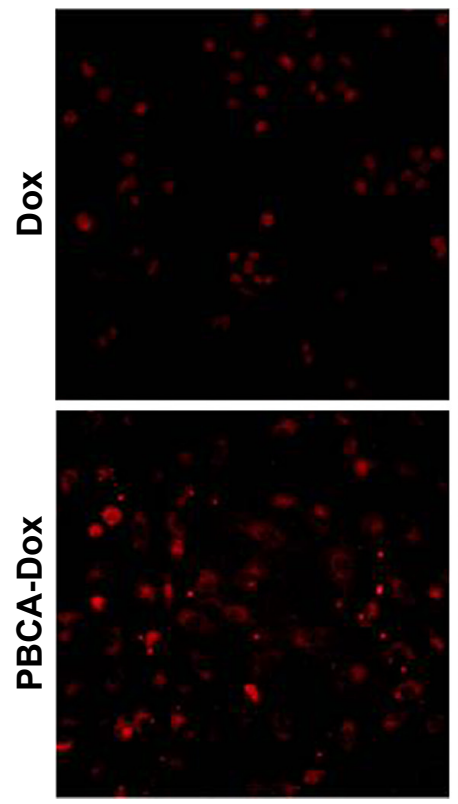

1.5 hours
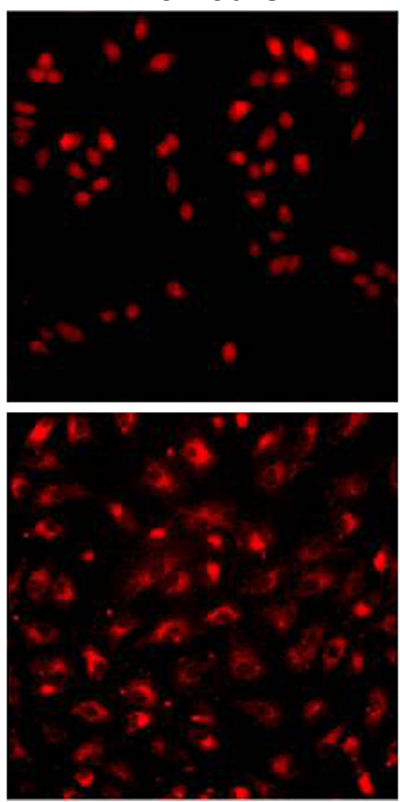

B

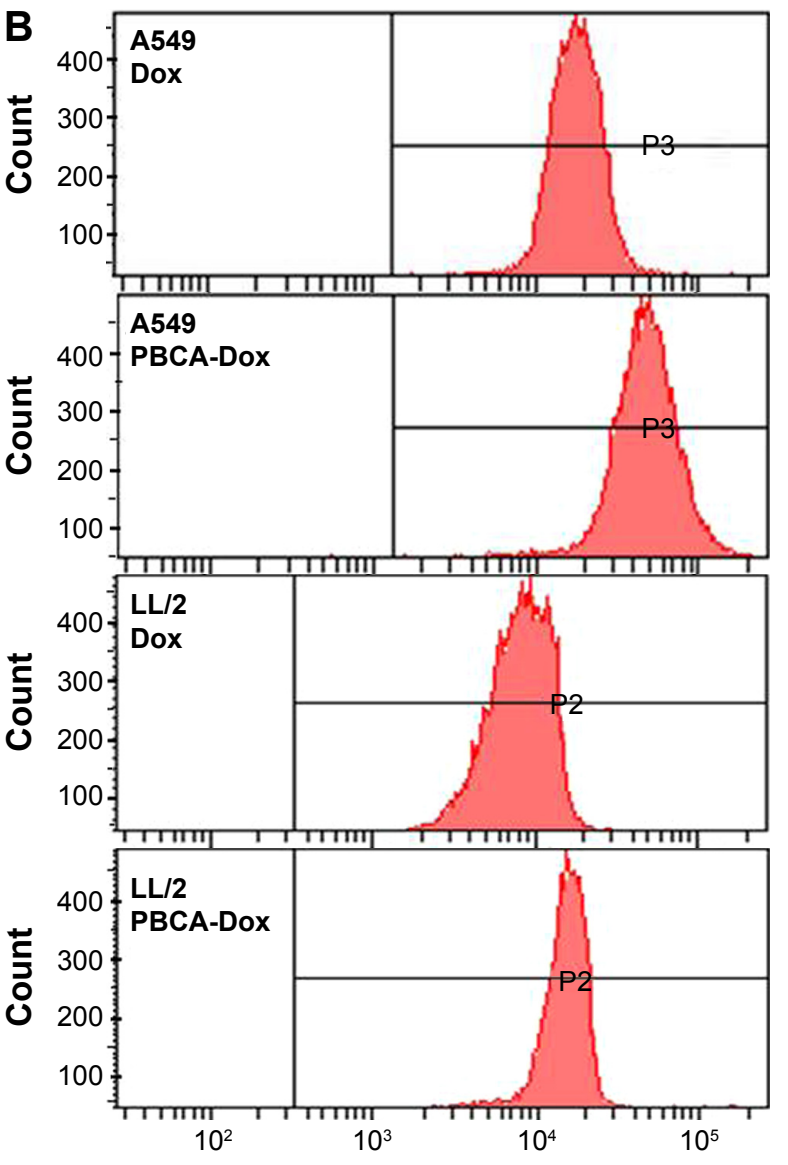

4 hours
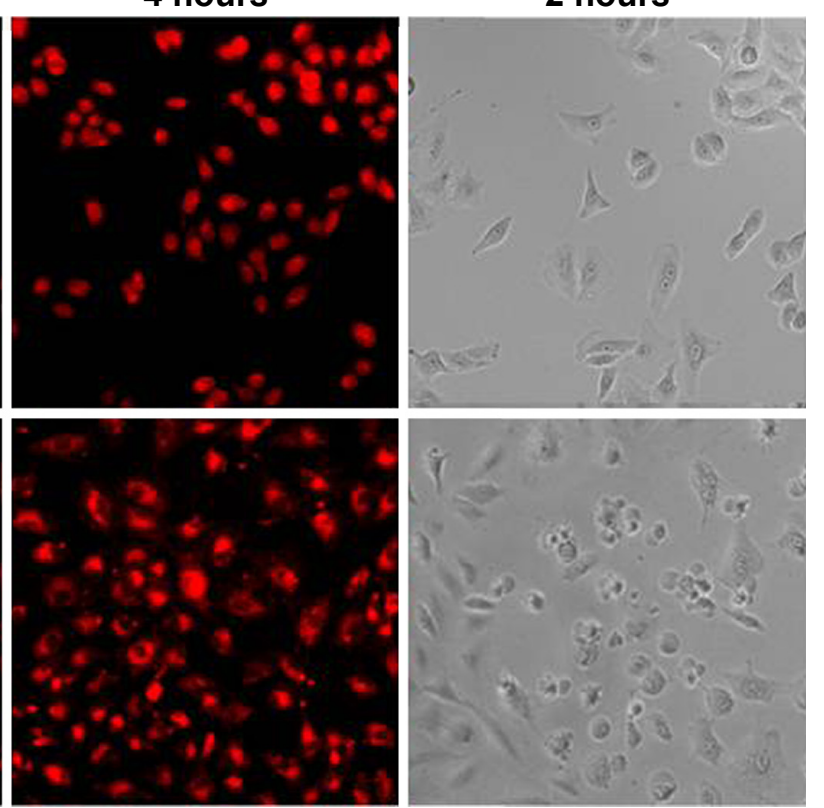

Figure 4 Uptake of Dox-loaded PBCA NPs into lung cancer cells.

Notes: (A) Graphical representation of the presence of Dox-loaded PBCA NPs and free Dox in A549 and LL/2 after exposure (0.5-4 hours) at the highest concentration $(43.1 \mu \mathrm{M})$. Data represent mean \pm SD of triplicate analysis. (B) Representative image of flow-cytometry analysis after exposure (4 hours) to Dox-loaded PBCA NPs and free Dox in A549 and LL/2. (C) Representative fluorescence images showing internalization of free Dox and Dox-loaded PBCA NPs in A549 cells for the highest concentration $(43.1 \mu \mathrm{M})$ over various times (0.5-4 hours). Optical microscopy analysis showed different morphological changes after Dox-loaded PBCA NP treatment in comparison to free Dox exposure. Magnification I0x.

Abbreviations: PE, phycoerythrin; Dox, doxorubicin; PBCA, poly(butylcyanoacrylate); NPs, nanoparticles; SD, standard deviation. 


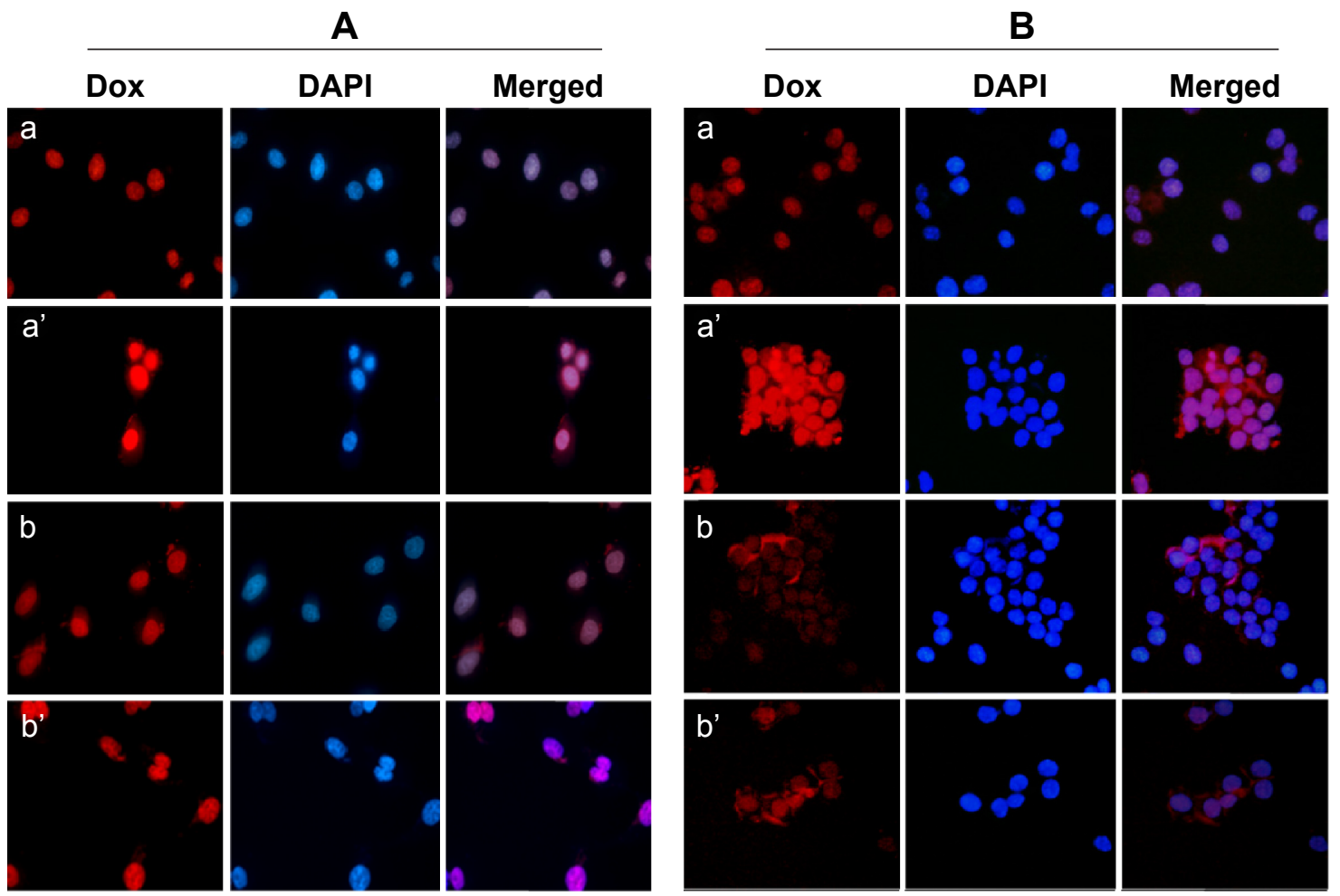

Figure 5 Intracellular location of free Dox and Dox-loaded PBCA NPs in A549 (A) and LL/2 (B) cell lines.

Notes: Cells were exposed for I hour to various treatments at the highest concentration of 43.I $\mu$ M with free Dox and Dox-loaded PBCA NPs (a, a', respectively) and $10 \mu \mathrm{M}$ (b, b', respectively). The first column shows drug-fluorescence images, the second shows cell nuclei stained with DAPI, and the third presents the merged images of the two previous columns. Magnification 20x.

Abbreviations: Dox, doxorubicin; PBCA, poly(butylcyanoacrylate); NPs, nanoparticles; DAPI, 4',6-diamidino-2-phenylindole.

results were found with LL/2 cells. However, in this cell line, the NPs determined a $22.6 \%$ increase in Dox uptake compared to free Dox after 0.5 hours of contact. By contrast, a negligible increase in cell uptake was observed after $1,1.5$, and 2 hours $(3.1 \%,-7.8 \%$, and $2.3 \%$, respectively). Finally, after 4 hours of NP-cell exposure, and in comparison to the free drug, Dox uptake by LL/2 cells increased by $32.1 \%$ when loaded into the PBCA NPs. These results were confirmed by fluorescence microscopy (Figure 5): increased fluorescence intensities were observed in cells treated with Dox-loaded PBCA NPs. Although drug accumulation at the cell nucleus was observed in the cells treated with either free Dox or Dox-loaded NPs, greater fluorescence intensities were shown in the cytoplasm of the cells treated with the Dox-loaded nanoformulation (particularly at the maximum drug-equivalent concentration).

\section{In vivo suppression of lung cancer tumor growth and mouse survival}

Blank (Dox-unloaded) PBCA NPs did not produce any significant change in tumor-volume progression compared to the control group (untreated mice) (Figure 6). In contrast, free Dox and Dox-loaded PBCA NPs significantly slowed tumor growth. In comparison to the controls, Dox-loaded PBCA NPs reduced mean tumor volume by $66 \%$ at the end of the experiment (39 days). This reduction was significantly greater (by $\sim 28 \%$ ) than that displayed by free Dox $(P<0.05)$. However, these differences were not extrapolated to mouse survival (Figure 6B), since no significant differences were observed between the groups treated with free Dox and Dox-loaded NPs. However, important differences in terms of mouse survival $(P<0.05)$ were found between these groups and the control groups. In addition, Dox entrapment within the NP matrix made it possible to reduce the drug's toxicity to mice at the end of the treatment $(P<0.05)$, which was measured in terms of weight loss (Figure 7). No weight differences were found between untreated mice and mice treated with blank PBCA NPs (data no shown).

\section{Discussion}

Nanoplatforms as Dox-delivery systems are expected to overcome the dose-dependent therapeutic limitations of this antitumoral agent. This may be particularly interesting for managing malignancies where this drug is used as a first- or 

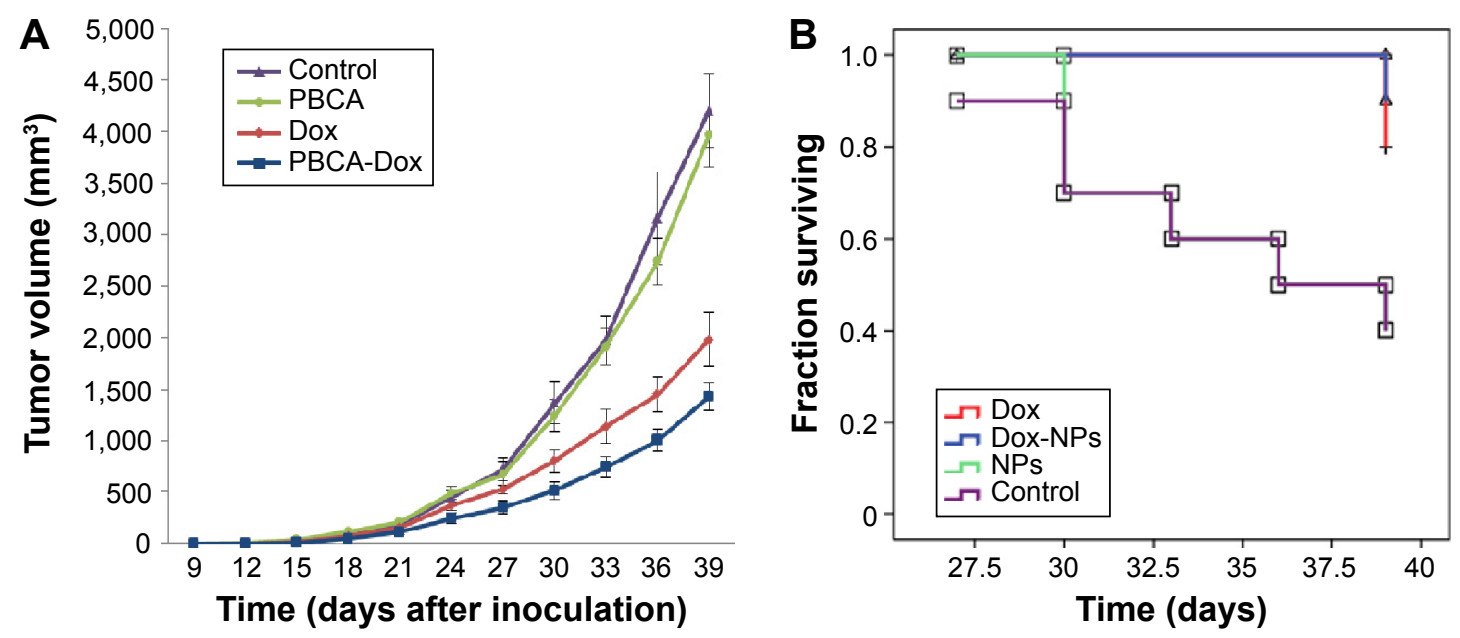

Figure 6 Tumor-growth inhibition and mouse survival after Dox-loaded PBCA NP treatment.

Notes: (A) Graphical representation of tumor-volume progression after intravenous administration of Dox-loaded PBCA NPs, free Dox, and blank PBCA NPs (I0 mg/kg) to C57BL/6 mice bearing subcutaneous tumors induced by LL/2 cells (39 days). Data represent mean $\pm S E M$ ( $n=10)$. (B) Difference in mouse-survival rates after exposure to the same treatments. Data represent mean \pm SD $(n=10)$. Comparison between treatment groups was performed with the log-rank test.

Abbreviations: Dox, doxorubicin; PBCA, poly(butylcyanoacrylate); NP, nanoparticle; SEM, standard error of mean; SD, standard deviation.

second-line treatment. In this context, we have developed an injectable two-phase drug-delivery system based on the biodegradable polymer PBCA for the sequential/controlled release of Dox. This system was previously engineered (by emulsion/polymerization of the cyanoacrylate monomer) for use against breast cancer cells, with promising results. ${ }^{22}$ However, significant modifications to the NP-engineering process introduced in the present work resulted in better NP functionalities, ie, reduced mean particle size (from the previously published $\sim 150$ to $\sim 75 \mathrm{~nm}$ in the present publication) and greater Dox-entrapment efficiencies (from $\sim 50 \%$

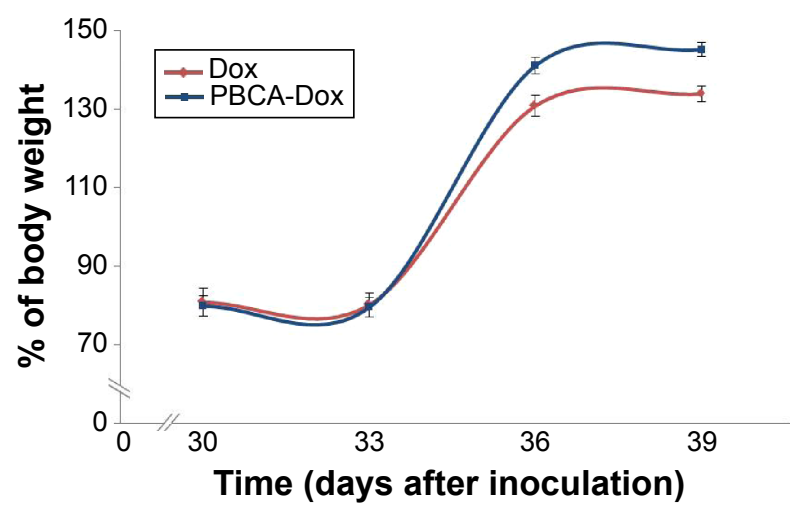

Figure 7 Percentage of body-weight progression after Dox-loaded PBCA NP treatment with respect to untreated mice.

Notes: Weight (g) of C57BL/6 mice bearing subcutaneous tumors induced by LL/2 cells and treated with Dox-loaded PBCA NPs, free Dox, and blank PBCA NPs were measured every 3 days over 39 days. Percentage of mouse body weight loss induced by treatment with DOX-loaded PBCA NPs was lower than that caused by free DOX. The data is represented as the mean \pm SD $(n=10)$.

Abbreviations: Dox, doxorubicin; PBCA, poly(butylcyanoacrylate); NP, nanoparticle; $\mathrm{SD}$, standard deviation. as earlier reported to $\sim 80 \%$ in this work). It is therefore possible to hypothesize much-improved in vitro and in vivo behavior: optimized NP uptake by malignant cells and Dox intracellular accumulation. ${ }^{30,31}$ These differences may arise from the modification of the synthesis conditions: mechanical stirring during monomer polymerization was carried out at 3,000 rpm (in contrast to $1,200 \mathrm{rpm}$ ), and the surfactant agent previously employed in NP formulation (Pluronic F-68, $1 \%, \mathrm{w} / \mathrm{v})$ was exchanged for dextran $70\left(0.5 \%\right.$, w/v). ${ }^{22}$ Moreover, the high drug-entrapment efficiency of our NPs allowed us to reach concentrations of Dox (similar to those presented in commercial preparations) that could have clinical application.

Dox incorporation into the PBCA nanomatrix may occur during NP formation, thanks to 1) the formation of hydrogen bonds between the drug's ammonium groups and the cyano groups of the PBCA NP, 2) the difficulty of drug molecules escaping from the growing polymeric network, and 3) the attractive interaction of the positively charged Dox molecules with the negative PBCA matrix. ${ }^{32-34}$ The sustained drugrelease profile the PBCA NPs (Figure 1) may have been the consequence of 1) rapid discharge of the Dox molecules on the surface of the NPs (fast-release phase, $\sim 35 \%$ Dox released in 1 hour) and 2) drug diffusion through the PBCA matrix (sequential second release phase ending after 23 hours)..$^{24,35}$

In vitro and in vivo activity of the nanoformulations against lung adenocarcinoma was investigated in A549 and LL/2 lung cancer cell lines. Blank (Dox-unloaded) PBCA NPs were found to be noncytotoxic in these cell lines, thus suggesting the adequate biocompatibility of the 
nanoformulations. These findings were confirmed in vivo. On the other hand, Dox-loaded NPs significantly reduced the $\mathrm{IC}_{50}$ value of the drug in both A549 and LL/2 cells in a time-dependent manner. Similar results have been previously obtained by an epirubicin-loaded PBCA nanoformulation in A549 cells. ${ }^{18}$ In addition, the PBCA NPs' capacity to increase drug cytotoxicity has recently been demonstrated using cisplatin (about three times as much cytotoxicity than free drug) against ovarian cancer cells. ${ }^{14}$ This cytotoxic effect could be associated with greater Dox uptake by the malignant cells when the drug is incorporated into the NP matrix.

In order to clarify the positive role that NPs may play in Dox uptake in cells, a flow-cytometry assay was performed using the same drug concentrations and various NP-cell contact times. Enhanced cell uptake of Dox was observed when it was loaded into the PBCA NPs (32.1\% and 64.8\% more in LL/2 and A549 cells, respectively) in comparison with the free Dox (aqueous solution) at the longest exposure time. This illustrates the key role played by the NPs in Dox incorporation into malignant cells. Fluorescence-microscopy analysis further demonstrated the different dispositions of the drug inside the tumor cells: the free drug was found exclusively within the cell nucleus, while Dox was distributed in the nucleus and cytoplasm of the cancer cells when the drug was entrapped inside the PBCA NPs. Similar findings have been described for the A549 lung cancer-cell line. ${ }^{18}$ The presence of Dox in the cytoplasm after delivery by the PBCA NPs could further maximize the drug toxicity through mitochondrial effects. In fact, Dox can interact in the respiratory chain complex I, increasing the oxidative stress generation of reactive oxygen species. ${ }^{36,37}$ The reactive oxygen species-level increase then results in an alteration of the mitochondrial transmembrane potential, in an increase in the mitochondrial permeability, and in a reduction of the ATP levels. ${ }^{36,38}$ Furthermore, Dox may interfere in metabolic pathways, such as glycolysis, $\beta$-oxidation, and oxidative phosphorylation, and induces the peroxidation of cell membranes. ${ }^{36,39}$

Subsequent work further suggested that NPs probably enter cancer cells through endocytosis. In fact, endocytosis, pinocytosis, and phagocytosis have been proposed to be the most important mechanisms behind cell uptake. ${ }^{40}$ They have been associated with the physical chemistry of the nanoformulations, ie, geometry and surface electrical charge. ${ }^{40,41}$ For instance, although positively charged NPs can interact easily with the (negative) cell membrane, they have been described to interact strongly in vivo with the immune system. Therefore, negatively charged or neutral NPs have been suggested as being more suitable for clinical applications. ${ }^{42,43}$
Geometrically, spherical shapes and nanosize particles (ie, gold NPs) have been described as positive characteristics for particle internalization by cancer cells. ${ }^{44}$ In addition, poly(alkylcyanoacrylate) NPs may be responsible for overcoming the multidrug-resistance mechanism displayed by cancer cells, associated with P-glycoprotein. For example, it has been demonstrated that blank PBCA NPs can decrease $\mathrm{P}$-glycoprotein function in a dose-dependent manner in A2780/T human ovarian-resistant cells and MCF-7/ADR human breast cancer cells. ${ }^{45,46}$ Similar activity may be expected for the Dox-loaded nanoformulation described in this work, but this has not yet been investigated.

Few in vivo studies have explored the potential clinical use of Dox-loaded PBCA NPs. As an example, PBCA NPs can improve the intratumor accumulation of Dox in Dalton's lymphoma-bearing mice compared to the free drug. ${ }^{47} \mathrm{PBCA}$ nanoformulations may be further responsible for reduced Dox toxicity in the heart, kidneys, and lungs. ${ }^{48}$ It has also been demonstrated that PBCA NPs can interact with alveolar macrophages, inducing increased secretion of Th1 cytokines (eg, IFN $\gamma$, IL-2), which may be related to a secondary cytotoxic effect on H460 non-small-cell lung carcinoma cells. ${ }^{49}$ In this work, the in vivo antitumoral activity of Dox-loaded PBCA NPs was analyzed in LL/2 lung carcinoma-bearing C57BL/6 mice. Compared to free Dox, there was significantly greater control over tumor-size progression in mice treated with the nanoformulation $(P<0.05)$, as well as a reduction in the drug-associated toxicity profile. These results confirmed the adequate toxicological profile previously reported for Dox-loaded PBCA NPs in comparison with the free drug. ${ }^{50,51}$ The NP system may optimize in vivo Dox incorporation into tumor cells. In fact, it has been hypothesized that nanoformulations could enhance drug accumulation in the tumor interstitium (compared to healthy tissues), thanks to the enhanced permeability and retention effect. ${ }^{52}$ As a consequence, the drug should display its cytotoxic effect almost entirely at the tumor site, thus keeping its severe side effects to a bare minimum. ${ }^{36,53}$

\section{Conclusion}

This work was devoted to developing an alkylcyanoacrylate nanoformulation for improved delivery of Dox to lung cancer cells. To this end, optimal and reproducible preparation conditions have been established for obtaining an injectable two-phase Dox-delivery system. In vitro studies have demonstrated the versatility of the NP system for facilitating drug internalization by lung carcinoma cells, optimizing the cytotoxic effect. Furthermore, in vivo investigations have 
highlighted promising control over tumor-size progression and the associated side effects displayed by the nanoformulation. For these reasons, the Dox-loaded NP system may help improve the current role of Dox in the therapeutic management of lung cancer patients.

\section{Acknowledgments}

This investigation was funded by FEDER, National Plan for Scientific Research, Development and Technological Innovation ( $\mathrm{I}+\mathrm{D}+\mathrm{I})$, Institute of Health Carlos III (FIS) through projects PI11/01862 and PI11/02571, and by the Andalusian Regional Ministry of Health through projects PI-0049 and P11-CTS-7649 (NP-synthesis experiences).

\section{Disclosure}

The authors report no conflicts of interest in this work.

\section{References}

1. American Cancer Society. Cancer Facts \& Figures 2013. Atlanta: American Cancer Society; 2013. Available from: http://www.cancer. org/acs/groups/content/@epidemiologysurveilance/documents/document/acspc-036845.pdf. Accessed November 14, 2015.

2. Grossi F, Gridelli C, Aita M, De Marinis F. Identifying an optimum treatment strategy for patients with advanced non-small cell lung cancer. Crit Rev Oncol Hematol. 2008;67(1):16-26.

3. Otterson GA, Villalona-Calero MA, Hicks W, et al. Phase I/II study of inhaled doxorubicin combined with platinum-based therapy for advanced non-small cell lung cancer. Clin Cancer Res. 2010;16(8):2466-2473.

4. Pilkington G, Boland A, Brown T, Oyee J, Bagust A, Dickson R. A systematic review of the clinical effectiveness of first-line chemotherapy for adult patients with locally advanced or metastatic non-small cell lung cancer. Thorax. 2015;70(4):359-367.

5. Wang Y, Zhang H, Hao J, Li B, Li M, Xiuwen W. Lung cancer combination therapy: co-delivery of paclitaxel and doxorubicin by nanostructured lipid carriers for synergistic effect. Drug Deliv. Epub 2015 Jun 24.

6. Wen G, Partridge MA, Li B, et al. TGFBI expression reduces in vitro and in vivo metastatic potential of lung and breast tumor cells. Cancer Lett. 2011;308(1):23-32.

7. Cai WK, Hu J, Li T, et al. Activation of histamine $\mathrm{H} 4$ receptors decreases epithelial-to-mesenchymal transition progress by inhibiting transforming growth factor- $\beta 1$ signalling pathway in non-small cell lung cancer. Eur J Cancer. 2014;50(6):1195-1206.

8. Filyak Y, Filyak O, Souchelnytskyi S, Stoika R. Doxorubicin inhibits TGF- $\beta$ signaling in human lung carcinoma A549 cells. Eur J Pharmacol. 2008;590(1-3):67-73.

9. Panis C, Herrera AC, Victorino VJ, Aranome AMF, Cecchini R. Screening of circulating TGF- $\beta$ levels and its clinicopathological significance in human breast cancer. Anticancer Res. 2013;33(2):737-742.

10. Tacar O, Sriamornsak P, Dass CR. Doxorubicin: an update on anticancer molecular action, toxicity and novel drug delivery systems. J Pharm Pharmacol. 2013;65(2):157-170.

11. Callaghan R, Luk F, Bebawy M. Inhibition of the multidrug resistance P-glycoprotein: time for a change of strategy? Drug Metab Dispos. 2014;42(4):623-631

12. Yang X, Yi C, Luo N, Gong C. Nanomedicine to overcome cancer multidrug resistance. Curr Drug Metab. 2014;15(6):632-649.

13. Prados J, Melguizo C, Ortiz R, et al. Doxorubicin-loaded nanoparticles new advances in breast cancer therapy. Anticancer Agents Med Chem. 2012;12(9):1058-1070.
14. Doun SK, Alavi SE, Esfahani MK, Shahmabadi HE, Alavi F, Hamzei S. Efficacy of cisplatin-loaded poly butyl cyanoacrylate nanoparticles on the ovarian cancer: an in vitro study. Tumour Biol. 2014;35(8): 7491-7497.

15. Tan R, Niu M, Zhao J, Liu Y, Feng N. Preparation of vincristine sulfateloaded poly (butylcyanoacrylate) nanoparticles modified with pluronic F127 and evaluation of their lymphatic tissue targeting. J Drug Target. 2014;22(6):509-517.

16. Yordanov G, Skrobanska R, Evangelatov A. Entrapment of epirubicin in poly(butyl cyanoacrylate) colloidal nanospheres by nanoprecipitation: formulation development and in vitro studies on cancer cell lines. Colloids Surf B Biointerfaces. 2012;92:98-105.

17. Yordanov G, Skrobanska R, Evangelatov A. Colloidal formulations of etoposide based on poly(butyl cyanoacrylate) nanoparticles: preparation, physicochemical properties and cytotoxicity. Colloids Surf B Biointerfaces. 2013;101:215-222.

18. Yordanov G, Evangelatov A, Skrobanska R. Epirubicin loaded to prepolymerized poly(butyl cyanoacrylate) nanoparticles: preparation and in vitro evaluation in human lung adenocarcinoma cells. Colloids Surf B Biointerfaces. 2013;107:115-123.

19. Kapse-Mistry S, Govender T, Srivastava R, Yergeri M. Nanodrug delivery in reversing multidrug resistance in cancer cells. Front Pharmacol. 2014;5:159.

20. Miao J, Du YZ, Yuan H, Zhang XG, Hu FQ. Drug resistance reversal activity of anticancer drug loaded solid lipid nanoparticles in multidrug resistant cancer cells. Colloids Surf B Biointerfaces. 2013;110: $74-80$.

21. Kolter M, Ott M, Hauer C, Reimold I, Fricker G. Nanotoxicity of poly(nbutylcyano-acrylate) nanoparticles at the blood-brain barrier, in human whole blood and in vivo. J Control Release. 2015;197:165-179.

22. Cabeza L, Ortiz R, Arias JL, et al. Enhanced antitumor activity of doxorubicin in breast cancer through the use of poly(butylcyanoacrylate) nanoparticles. Int J Nanomedicine. 2015;10:1291-1306.

23. O'Brien RW, White LR. Electrophoretic mobility of a spherical colloidal particle. J Chem Soc Faraday Trans. 1978;2(74):1607-1626.

24. Arias JL, RuizMA,López-Viota M,Delgado AV.Poly(alkylcyanoacrylate) colloidal particles as vehicles for antitumour drug delivery: a comparative study. Colloids Surf B Biointerfaces. 2008;62(1):64-70.

25. Skehan P, Storeng R, Scudiero D, et al. New colorimetric cytotoxicity assay for anticancer-drug screening. J Natl Cancer Inst. 1990;82(13): 1107-1112.

26. Arias JL, Gallardo V, Linares-Molinero F, Delgado AV. Preparation and characterization of carbonyl iron/poly(butylcyanoacrylate) core/ shell nanoparticles. J Colloid Interface Sci. 2006;299(2):599-607.

27. Arias JL, Gallardo V, Ruiz MA, Delgado AV. Ftorafur loading and controlled release from poly(ethyl-2-cyanoacrylate) and poly(butylcyanoacrylate) nanospheres. Int J Pharm. 2007;337(1-2): 282-290.

28. Couvreur P. Polyalkylcyanoacrylates as colloidal drug carriers. Crit Rev Ther Drug Carrier Syst. 1988;5(1):1-20.

29. Vauthier C, Dubernet C, Fattal E, Pinto-Alphandary H, Couvreur P. Poly(alkylcyanoacrylates) as biodegradable materials for biomedical applications. Adv Drug Deliv Rev. 2003;55(4):519-548.

30. Huang C, Zhang Y, Yuan H, Gao H, Zhang S. Role of nanoparticle geometry in endocytosis: laying down to stand up. Nano Lett. 2013;13(9): 4546-4550.

31. Kettler K, Veltman K, van de Meent D, van Wezel A, Hendriks AJ. Cellular uptake of nanoparticles as determined by particle properties, experimental conditions, and cell type. Environ Toxicol Chem. 2014; 33(3):481-492.

32. Poupaert JH, Couvreur P. A computationally derived structural model of doxorubicin interacting with oligomeric polyalkylcyanoacrylate in nanoparticles. J Control Release. 2003;92(1-2):19-26.

33. Yu MK, Jeong YY, Park J, et al. Drug-loaded superparamagnetic iron oxide nanoparticles for combined cancer imaging and therapy in vivo. Angew Chem Int Ed Engl. 2008;47(29):5362-5365. 
34. Gaihre B, Khil MS, Lee DR, Kim HY. Gelatin-coated magnetic iron oxide nanoparticles as carrier system: drug loading and in vitro drug release study. Int J Pharm. 2009;365(1-2):180-189.

35. Graf A, McDowell A, Rades T. Poly(alkylcyanoacrylate) nanoparticles for enhanced delivery of therapeutics - is there real potential? Expert Opin Drug Deliv. 2009;6(4):371-387.

36. Carvalho FS, Burgeiro A, Garcia R, Moreno AJ, Carvalho RA, Oliveira PJ. Doxorubicin-induced cardiotoxicity: from bioenergetic failure and cell death to cardiomyopathy. Med Res Rev. 2014;34(1):106-135.

37. Mordente A, Meucci E, Silvestrini A, Martorana GE, Giardina B. Anthracyclines and mitochondria. Adv Exp Med Biol. 2012;942:385-419.

38. Gharanei M, Hussain A, Janneh O, Maddock HL. Doxorubicin induced myocardial injury is exacerbated following ischaemic stress via opening of the mitochondrial permeability transition pore. Toxicol Appl Pharmacol. 2013;268(2):149-156.

39. Stěrba M, Popelová O, Lenčo J, et al. Proteomic insights into chronic anthracycline cardiotoxicity. J Mol Cell Cardiol. 2011;50(5): 849-862.

40. Ma N, Ma C, Li C, et al. Influence of nanoparticle shape, size, and surface functionalization on cellular uptake. J Nanosci Nanotechnol. 2013;13(10):6485-6498.

41. Zhang Y, Xu D, Li W, Yu J, Chen Y. Effect of size, shape, and surface modification on cytotoxicity of gold nanoparticles to human HEp-2 and canine MDCK cells. J Nanomater. 2012;2012:375496.

42. Gratton SE, Ropp PA, Pohlhaus PD, et al. The effect of particle design on cellular internalization pathways. Proc Natl Acad Sci US A. 2008;105(33):11613-11618.

43. He C, Hu Y, Yin L, Tang C, Yin C. Effects of particle size and surface charge on cellular uptake and biodistribution of polymeric nanoparticles. Biomaterials. 2010;31(13):3657-3666.

44. Chithrani BD, Ghazani AA, Chan WC. Determining the size and shape dependence of gold nanoparticle uptake into mammalian cells. Nano Lett. 2006;6(4):662-668.
45. Ren F, Chen R, Wang Y, Sun Y, Jiang Y, Li G. Paclitaxel-loaded poly(nbutylcyanoacrylate) nanoparticle delivery system to overcome multidrug resistance in ovarian cancer. Pharm Res. 2011;28(4):897-906.

46. Duan J, Mansour HM, Zhang Y, et al. Reversion of multidrug resistance by co-encapsulation of doxorubicin and curcumin in chitosan/poly(butyl cyanoacrylate) nanoparticles. Int J Pharm. 2012;426(1-2):193-201.

47. Reddy LH, Sharma RK, Murthy RS. Enhanced tumour uptake of doxorubicin loaded poly(butyl cyanoacrylate) nanoparticles in mice bearing Dalton's lymphoma tumour. J Drug Target. 2004;12(7): 443-451.

48. Shen L, Zhang Y, Shen H, et al. Liver targeting and the delayed drug release of the nanoparticles of adriamycin polybutylcyanoacrylate in mice. Chin Med J (Engl). 2006;119(15):1287-1293.

49. Al-Hallak KM, Azarmi S, Anwar-Mohamed A, Roa WH, Löbenberg R. Secondary cytotoxicity mediated by alveolar macrophages: a contribution to the total efficacy of nanoparticles in lung cancer therapy? Eur J Pharm Biopharm. 2010;76(1):112-119.

50. Pereverzeva E, Treschalin I, Bodyagin D, et al. Influence of the formulation on the tolerance profile of nanoparticle-bound doxorubicin in healthy rats: focus on cardio- and testicular toxicity. Int J Pharm. 2007;337(1-2):346-356.

51. Pereverzeva E, Treschalin I, Bodyagin D, Maksimenko O, Kreuter J, Gelperina S. Intravenous tolerance of a nanoparticle-based formulation of doxorubicin in healthy rats. Toxicol Lett. 2008;178(1):9-19.

52. Wang M, Thanou M. Targeting nanoparticles to cancer. Pharmacol Res. 2010;62(2):90-99.

53. Jain RK, Stylianopoulos T. Delivering nanomedicine to solid tumors. Nat Rev Clin Oncol. 2010;7(11):653-664.
Drug Design, Development and Therapy

\section{Publish your work in this journal}

Drug Design, Development and Therapy is an international, peerreviewed open-access journal that spans the spectrum of drug design and development through to clinical applications. Clinical outcomes, patient safety, and programs for the development and effective, safe, and sustained use of medicines are a feature of the journal, which

\section{Dovepress}

has also been accepted for indexing on PubMed Central. The manuscript management system is completely online and includes a very quick and fair peer-review system, which is all easy to use. Visit http://www.dovepress.com/testimonials.php to read real quotes from published authors. 